\title{
TEORIA E PRÁTICA NO ÂMBITO DO ENSINO MÉDIO: ANÁLISE DE CASOS NO PIAUÍ E CEARÁ PARA O ENSINO DE BIOLOGIA
}

\author{
THEORY AND PRACTICE IN HIGH SCHOOL: CASES ANALYSIS IN PIAUÍ \\ AND CEARÁ FOR BIOLOGY TEACHING
}

\begin{abstract}
Polyanna Milany Santos Pimentel
Instituto Federal de Educação, Ciência e Tecnologia do Piauí - IFPI, Licenciatura em Ciências

Biológicas, email: polyannamilany@gmail.com

Marcos Vinícius Pereira Oliveira

Universidade Federal do Ceará - UFC, Departamento de Ciências Sociais, email: markin_the@hotmail.com

\section{Emanoela Moreira Maciel}

Instituto Federal de Educação, Ciência e Tecnologia do Piauí - IFPI, Licenciatura em Ciências Biológicas, email: emanoela@ifpi.edu.br
\end{abstract}

\section{Resumo}

Neste artigo analisamos como os professores de Biologia da rede pública estadual estão em efetiva ação conciliando teoria e prática no contexto do ensino médio, considerando a realidade de duas escolas: Escola Estadual de Ensino Fundamental e Médio Figueiredo Correia em Fortaleza, no Ceará, e a Unidade Escolar Gabriel Ferreira em Teresina, no Piauí. A pesquisa é fruto de observações e experiências em estágios durante a graduação que nos levaram a questionar o processo de ensino-aprendizagem dos discentes em relação à teoria aliada a prática. Utilizamos uma abordagem predominantemente qualitativa, mas tendo a perspectiva quantitativa como suporte essencial para análise dos dados. Constatou-se que a teoria aliada à prática no ensino de Biologia ainda é deficiente nas escolas estudadas, inclusive, um importante fator identificado refere-se a ausências e deficiências, na formação continuada dos professores no sentido da capacitação destes para transmissão de um ensino de qualidade, em interconexão entre duas perspectivas: teórico-conceitual e a prática, ligada ao cotidiano. Nesse sentido, o uso de novas metodologias mostra-se como um caminho possível nesta direção, além da possibilidade de maior contextualização e interdisciplinaridade de fato, para o ensino de biologia no âmbito do Ensino Médio.

Palavras-chave: Teoria. Prática. Novas Metodologias. Ensino de Biologia. Ensino Médio. 


\section{Abstract}

In this article we analyze how the biology teachers of public schools are in effective action combining theory and practice in high school context, considering the reality of two schools: Escola Estadual de Ensino Fundamental e Médio Figueiredo Correia in Fortaleza, Ceará, and Unidade Escolar Gabriel Ferreira in Teresina, Piauí. The research is the result of observations and experiments on internships during graduation that led us to question the teaching and learning process of students in relation to the theory combined with practice. We use a predominantly qualitative approach, but taking a quantitative perspective as an essential support for data analysis. It was found that the theory together with the practice in teaching biology is still deficient in the schools, including an important factor identified relates to absences and bad formation, continuing education of teachers towards training of these for transmission of a qualified teaching of interconnection between two perspectives: theoretical and conceptual and practice, linked to everyday life. In this direction, the use of new methodologies is shown as a possible way in this direction, and the possibility of greater contextualization and interdisciplinarity actually to biology teaching as part of high school.

Keywords: Theory. Practice. New Methodologies. Biology Teaching. High School.

\section{Introdução}

A ideia que estimulou a proposta do presente trabalho científico surgiu de nossas experiências em estágios no ensino médio relacionados à prática docente, no âmbito da graduação em Licenciatura Plena em Ciências Biológicas, do Instituto Federal de Educação, Ciência e Tecnologia do Piauí - IFPI. Assim também como as atividades desenvolvidas dentro do Programa Institucional de Bolsas de Iniciação à Docência - PIBID deram continuidade aos questionamentos em relação à teoria aliada a prática como uma ferramenta eficaz de fundamental importância para o desenvolvimento da aprendizagem dos alunos.

Durante o processo dos estágios foi possível observar o quanto os conteúdos de biologia tornavam-se distantes de algo concreto para os alunos, e que as aulas práticas não faziam parte da realidade escolar. Diante desse contexto a pesquisa em questão tem como objetivo investigar como os professores de Biologia têm articulado a teoria com a prática no ensino de Biologia, no ensino médio da rede pública estadual. Para esta questão trabalhamos como lócus empírico as escolas estaduais Figueiredo Correia em Fortaleza, no Estado do Ceará, e a escola estadual Gabriel Ferreira em Teresina, no Piauí.

Para tanto, buscamos compreender através da observação, das falas dos alunos e de questionários, indicativos de uma aprendizagem significativa, associada ao que é repassado pelo professor em sala de aula com a realidade cotidiana do aluno; observar a questão da interdisciplinaridade e a contextualização da Biologia com as demais disciplinas; descrever aspectos relacionados à estrutura e as instalações das escolas estudadas; identificar incentivos quanto à formação continuada para os professores nas escolas analisadas. 
Tendo como ponto de partida a realidade escolar dos dois estados em questão, Piauí e Ceará, o presente trabalho possui relevante importância por se tratar de uma temática que visa auxiliar os docentes a repensar suas estratégias de ensino no campo da disciplina de biologia tornando-se efetiva a ação de aliar teoria e prática. É importante destacar que os professores de biologia enfrentam dificuldades no processo educativo dos alunos, como, por exemplo, em possibilitar ao aluno a participação em discussões contemporâneas que exijam conhecimento biológico, como também na contribuição da formação do indivíduo, para que este possa ter um sólido conhecimento de Biologia e raciocínio crítico, entre outros desafios.

As escolas precisam de recursos que estejam ao alcance do professor para oferecer um ensino de qualidade. No ensino de Biologia além de outros equipamentos e recursos didáticos, o laboratório constitui uma ferramenta essencial que deve vir acompanhado de professores qualificados para a realização das atividades (PAGLIARINE, et al, 2013).

É grande o número de trabalhos que tratam da problemática da conciliação entre teoria e prática em nossa realidade educacional. No entanto, sobretudo no que tange ao ensino de Biologia no ensino médio e a comparação de duas realidades, uma escola do Estado do Piauí e outra do Ceará, esta proposta de pesquisa é inovadora por tratar a temática pelo prisma da tentativa de entender essas duas realidades, no que se refere a teoria e a prática no ensino de Biologia no âmbito do ensino médio público.

Portanto, a pesquisa visa ressaltar também a importância do professor de Biologia, que mesmo frente aos desafios contemporâneos, assume um papel essencial na busca de novas perspectivas de ensino. Assim, conciliar a teoria com a prática, de fato torna-se fundamental para um ensino mais qualitativo e contextualizado para os alunos.

\section{Considerações prévias sobre teoria e prática no ensino de biologia}

O ensino de Biologia, em sua fundamentação, requer uma relação constante entre a teoria e a prática, entre conhecimento científico e o mundo ao nosso redor. Essas relações são de extrema importância, uma vez que a disciplina de Ciências e/ou Biologia verifica-se subtendido como uma ciência experimental, de comprovação científica, articulada a pressupostos teóricos e com isso advém a ideia de que a realização de experimentos é difundida como uma grande estratégia didática para seu ensino e aprendizagem (BUENO e KOVALICZN, 2008). No entanto, não deve ser vista como a prática pela prática, de forma utilitária, e sim uma prática transformadora, adaptada à realidade dos alunos, e com objetivos bem definidos (KOVALICZN, 1999).

Podemos dizer que o objeto de estudo da Biologia configura-se no fenômeno vida em toda sua diversidade, ou seja, em todos os seus níveis: ecossistemas, populações, espécies, genes (BRASIL, 2006). Assim, o conhecimento de Biologia, além de tratar questões estritamente biológicas, também deve dar base e propiciar uma análise crítica de questões polêmicas e de cunho político, a ela relacionada, como por exemplo, a biodiversidade brasileira, e seus usos e saberes que fazem parte da realidade de grupos tradicionais, como os povos indígenas (BRASIL, 2006). 
Portanto, a questão de aliar a teoria com a prática vai além de experimentos laboratoriais, e de conteúdos exclusivamente biológicos. Dessa forma, o professor além de trabalhar com conteúdos chaves da biologia, deve também utilizar a disciplina como instrumento para propiciar a interdisciplinaridade entre as outras áreas do conhecimento.

\section{A Interdisciplinaridade e as novas metodologias}

Segundo Jairo Gonçalves Carlos a interdisciplinaridade corresponde a "uma espécie de interação entre as disciplinas ou áreas do saber" (CARLOS, 2007, p. 162). É importante destacar que a interdisciplinaridade propõe interconexões, convergência e ligações fundamentais entre os conhecimentos, ou seja, a medida em que o professor contempla de certa forma a contextualização e a interdisciplinaridade no seu exercício como educador estará capacitando o aluno para a vida em sociedade, a atividade produtiva e experiências subjetivas, visando a integração com seu meio ( FORTES, 2009).

Nesse sentido os fatores que contemplam o uso da interdisciplinaridade justificam-se pela busca de novas possibilidades para o ensino de biologia, isto é, o uso de novas metodologias que venham auxiliar a aprendizagem dos alunos de forma significativa (OLIVEIRA e DANTAS, 2014). Temos como exemplo, no âmbito do Instituto Federal do Piauí, o trabalho de conclusão de curso de Vanessa Havena Muniz de Oliveira, intitulado "Biologia em verso e prosa: ensinando através de cordéis", que aborda a temática do ensino de biologia com a utilização da literatura de cordel. Para esta autora, o cordel se apresenta como uma dessas novas possibilidades para o ensino de biologia, pois dinamiza a maneira com a qual se ensina e facilita o processo de ensino-aprendizagem (OLIVEIRA e DANTAS, 2014).

Nesse sentido, a utilização de novas metodologias pode ser uma construção viável para a realidade de muitos no contexto da escola pública, além de contribuir para a formação do educando, o que acaba por proporcionar a interdisciplinaridade, ao mesmo tempo em que a biologia se realiza aliando teoria com a prática, objeto de estudo deste trabalho.

\subsection{Dificuldades e desafios, um olhar crítico}

De acordo com Fortes (2009), a educação deve romper com a compartimentalização entre as disciplinas, para mostrar as correlações entre os saberes, a vida em sua complexidade e os problemas que permeiam nosso sistema educacional. Caso contrário, será sempre ineficiente e insuficiente para os cidadãos do futuro. Somando-se a isso o ensino de Biologia necessita de uma intensa correlação com a realidade fora do ambiente escolar.

Em relação às aulas práticas, experimentos e demonstrações em sala de aula podemos observar que o ensino público ainda demonstra deficiência na prática de ensino da Biologia, sendo fator de suma importância na aprendizagem e na assimilação dos conteúdos (GONZAGA, et al, 2012) 
Um dos fatores que têm prejudicado a aprendizagem dos conteúdos de Biologia nas escolas públicas está relacionado aos recursos didáticos, pois apesar de existirem várias opções para serem utilizadas pelos professores na intenção de alcançar os objetivos da disciplina como, quadro negro, retroprojetores, vídeos, computadores, ainda existe o problema quanto a quantidade, e disponibilidade desses recursos dentro dos estabelecimentos de ensino, (SILVA, et al, 2013). Além disso, existe o fato de não haver uma formação inicial e continuada quanto à capacitação técnica para os professores, no que se refere ao manuseio dos equipamentos disponíveis, já que no contexto atual de nossa sociedade exigem-se novas demandas, nas quais o professor, além de ter uma boa formação em sua área do conhecimento, precisa também dispor de conhecimentos técnicos para utilização dos recursos tecnológicos que a escola venha dispor.

Outro fator que também acaba por dificultar o aprendizado dos alunos refere-se à questão da dificuldade dos professores em trabalharem com uma nomenclatura específica em relação aos termos científicos da Biologia, pois como dito por Silva et al (2013):

Os termos científicos muitas vezes são considerados desnecessários para o ensino desta disciplina, o que configura um erro, pois é preciso que o professor tente apresentá-los aos seus alunos de forma correta e sempre difundir seu significado (SILVA, et al, 2013, p.139).

Nesse sentido torna-se necessário um aprofundamento em termos específicos da Ciência Biológica, do qual o professor não deve esquivar-se. Somando-se a isso, deve ser objetivo do professor capacitar o educando para interpretar fatos e fenômenos - naturais ou não - sob a óptica da ciência, mais especificamente da Biologia, para que, simultaneamente, adquira uma visão crítica que lhe permita tomar decisões usando sua instrução nessa área do conhecimento (BRASIL, 2006).

Com base na visão de Borges apud Zamunaro (2006), muitos professores acreditam que o ensino de Biologia poderia ser melhorado se houvessem mais aulas práticas nas escolas, entretanto, muitas vezes, a escola, mesmo possuindo laboratórios, não utilizam com frequência. Para Resende (2007), os professores de Biologia devem recorrer às aulas práticas na intenção de dinamizar o ensino dessa disciplina.

As aulas práticas podem ajudar no desenvolvimento de conceitos científicos, além de permitir que os estudantes aprendam como abordar objetivamente o seu mundo e como desenvolver soluções para problemas complexos (SILVA, et al2013 p.140).

Com relação às atividades práticas realizadas em laboratório, é necessário observar que o ideal seria a participação do aluno em todas as etapas da atividade, inclusive na proposição do procedimento a ser seguido (BRASIL, 2006). Teoria e prática devem andar juntas, aulas teóricas e atividades práticas se completam, reforçam e garantem a solidez dos conhecimentos adquiridos, tornando-se assim indispensável o uso de laboratórios (GONZAGA, et al, 2012). Portanto, o uso de laboratórios é essencial para articulação de fato entre teoria e prática, na busca de um conhecimento transformador, tendo como base a experiência adquirida pelos alunos. 


\subsection{A Unicidade entre teoria e prática}

Teoria e prática são elementos imbricados. A unicidade dos dois polos sejam eles, teoria e prática são de suma importância para a prática pedagógica (TEIXEIRA e OLIVEIRA, 2008). Teoria e prática, portanto, são indissolúveis, ou seja, "tem um lado ideal, teórico e um lado material, propriamente prático, com a particularidade de que só artificialmente, por um processo de abstração, podemos separar um do outro" (TEIXEIRA e OLIVEIRA, 2008, p. 3).

Contudo, a relação entre teoria e prática tem sido trabalhada frequentemente nas escolas de maneira desarticulada.

A separação, e mesmo oposição, entre teoria e prática é frequentemente denunciada pelos educadores, ao mesmo tempo em que é explicitado o desejo de buscar novas formas de relacionamento entre essas duas dimensões da realidade. A visão de unidade expressa à síntese superadora da dicotomia entre teoria e prática, sendo condição fundamental para a busca de alternativas na formação do educador (TEIXEIRA e OLIVEIRA, 2008, p. 3).

É nessa perspectiva de unidade que se deve trabalhar teoria e prática, para não perder a "visão de totalidade da prática pedagógica e da formação como forma de eliminar distorções decorrentes da priorização de um dos dois polos" (TEIXEIRA e OLIVEIRA, 2008).

Seguindo essa direção, a realidade atual em torno das escolas públicas deve seguir novos caminhos, em relação à teoria e prática, especificamente, no estudo em questão, no ensino de Biologia. Portanto, é necessário que os professores estejam em permanente formação continuada.

Trata-se de capacitar um professor como um profissional prático-reflexivo que se defronta com situações de incertezas, contextualizadas e únicas, o que recorre à investigação como uma forma de decidir e de intervir praticamente em tais situações e que faz emergir novos discursos teóricos e concepções alternativas de formação (IMBERNÓN, 2010). Assim, "Uma formação deve propor um processo que confira ao docente, conhecimentos, habilidades e atitudes para criar profissionais reflexivos ou investigadores" (IMBERNÓN, 2010 p.41).

Portanto, podemos evidenciar que a relação entre teoria e prática se constitui como fator de unidade indissolúvel não só no que tange ao ensino de biologia, mas também no ensino das outras áreas do conhecimento. Nesse sentido o professor no âmbito do ensino público precisa estar em intensa capacitação, aprimorando seu aprendizado como investigador e desenvolvendo a interdisciplinaridade com o uso de novas metodologias de ensino com a finalidade de proporcionar ao aluno uma aprendizagem significativa, ou seja, onde o discente inter-relacione a aprendizagem em sala de aula com sua realidade coletiva e individual.

Assim, o professor estará auxiliando o aluno a adquirir uma visão crítica que the permita tomar decisões, utilizando-se dos conhecimentos adquiridos em biologia que, por 
consequência da ação de contextualização e interdisciplinaridade estará interligada às outras disciplinas. Diante disso uma interação entre teoria e prática revela-se um ensino transformador para a educação em sentido amplo que dará base às gerações futuras.

\section{Procedimentos metodológicos}

O estudo aqui em evidência teve como objetivo investigar como os professores de Biologia da rede pública de ensino estão em efetiva ação conciliando a teoria com a prática no ensino de Biologia no contexto do ensino médio, considerando a realidade de duas Escolas Estaduais: Figueiredo Correia em Fortaleza, no Ceará, e a escola Gabriel Ferreira em Teresina, no Piauí.

A pesquisa e seus estudos norteadores tiveram por base metodológica o encaminhamento teórico da pesquisa qualitativa, sem desprezar o auxílio da abordagem quantitativa que garantiu também grande suporte para o estudo (APPOLINARIO, 2006; GOLDENBERG, 2001). Utilizou-se para esse estudo a aplicação de questionários como instrumento de coleta de dados, a partir de questões formuladas (MARTINS JUNIOR, 2010), além da realização de entrevistas. Os questionários foram aplicados somente para os alunos, e as entrevistas foram realizadas com alguns alunos e os professores da disciplina.

$\mathrm{Na}$ elaboração do questionário levou-se em consideração que a construção de um bom questionário depende não só do conhecimento de técnicas, mas principalmente da experiência do pesquisador, no entanto, seguir um método de elaboração, sem dúvida é essencial, pois identifica as etapas básicas envolvidas na construção de um instrumento eficaz para a pesquisa (CHAGAS, 2000). É necessário que se estabeleça também uma ligação com o problema, os objetivos e com as hipóteses da pesquisa, a população a ser pesquisada e com os métodos de análise de dados escolhidos e/ou disponíveis (CHAGAS, 2000). Portanto, para a construção do questionário foi necessário avaliar e expor este objeto de pesquisa a revisões contínuas com o objetivo de ser uma ferramenta de aplicação eficaz dentro da proposta de pesquisa.

Como lócus empírico trabalhou-se com duas escolas estaduais como dito antes Figueiredo Correia em Fortaleza, no Ceará, e a escola Gabriel Ferreira em Teresina, no Piauí, com a intenção de comparar as duas realidades à nível estadual, no que tange ao exercício de aliar a teoria com a prática para o ensino de Biologia no ensino médio. Esta escolha se deu ao fato de termos melhor acesso a estas escolas, pois realizamos estágio supervisionado em ambas, além de conhecermos boa parte da equipe e ter participado também dessa realidade escolar.

Neste trabalho utilizamos também da observação direta (APPOLINARIO, 2006; MARTINS JUNIOR, 2010) entrando em contato com o fenômeno estudado, recorremos também a um diário onde foram feitas anotações de nossas observações, e de um gravador de voz para realização das entrevistas com professores e alunos. Por fim, seguindo orientações éticas garantimos o anonimato dos pesquisados se requerido por eles, além 
disso, prestamos todas as informações referentes à pesquisa com intuito de garantir a liberdade dos pesquisados de participarem da pesquisa ou não.

\section{Apresentação e análise dos dados}

$\mathrm{Na}$ perspectiva de alcançar resultados, diante dos questionamentos presentes na temática da pesquisa em questão, na qual investigamos como os professores de Biologia da rede pública de ensino estão em efetiva ação conciliando a teoria com a prática no ensino de Biologia, no contexto do ensino médio, considerando a realidade de duas escolas Estaduais: Figueiredo Correia em fortaleza, no Ceará, e a escola Gabriel Ferreira em Teresina, no Piauí. Assim, observamos através das análises dos questionários aplicados e das entrevistas realizadas com alunos e professores a grande deficiência que essas escolas apresentam no que se refere aliar a teoria com a prática no contexto da disciplina Biologia.

$\mathrm{Na}$ análise dos questionários aplicados nas escolas foi possível identificar alguns pontos relevantes que demonstram bem a realidade escolar no que se refere aliar teoria à prática no ensino de Biologia no âmbito do ensino médio. Após aplicação dos questionários nas escolas também foi realizado o processamento das informações colhidas, no qual, organizamos em quadros para a tabulação dos dados com base em Martins Júnior (2010).

No primeiro quadro organizamos os dados referentes à perspectiva dos alunos em relação a possibilidade de se estabelecer uma relação entre a Biologia e sua realidade fora do ambiente escolar. Dessa forma, verificamos que na escola Figueiredo Correia no Ceará $63 \%$ dos alunos afirmaram que conseguem sim estabelecer uma relação entre a Biologia e seu cotidiano fora da escola e $37 \%$ constataram que não conseguem estabelecer essa relação.

Quadro 1 - Perspectiva dos alunos em relação a possibilidade de relação entre a Biologia e a realidade fora do contexto escolar.

\begin{tabular}{|c|c|c|c|c|c|c|}
\hline & \multicolumn{2}{|c|}{$\begin{array}{c}\text { Figueiredo Correia } \\
\text { (Fortaleza) }\end{array}$} & \multicolumn{2}{c|}{$\begin{array}{c}\text { Gabriel Ferreira } \\
\text { (Teresina) }\end{array}$} & \multicolumn{2}{c|}{ Total } \\
\hline RESPOSTAS & Frequência & $\%$ & Frequência & $\%$ & Frequência & $\%$ \\
\hline Sim & 39 & 63 & 54 & 65 & 93 & 64 \\
\hline Não & 23 & 37 & 30 & 35 & 53 & 36 \\
\hline Total & 62 & 100 & 84 & 100 & 146 & 100 \\
& & & & & & \\
\hline
\end{tabular}

Fonte: Realizada pelos autores.

Na escola Gabriel Ferreira no Piauí, diante da mesma questão abordada $65 \%$ dos alunos afirmaram também ser possível estabelecer uma relação entre a Biologia e o 
contexto fora do âmbito escolar, e 35\% disseram que essa relação não seria possível. No total constatou-se que $64 \%$ dos alunos, tanto da escola Figueiredo Correia, no Ceará quanto na escola Gabriel Ferreira, no Piauí afirmam ser possível se estabelecer uma relação entre a Biologia e o meio fora do âmbito escolar. Diante desse resultado foi possível constatar também a importância da Biologia para os alunos, fato também observado nas respostas abertas dos questionários aplicados, como na observação de um aluno do $1^{\circ}$ ano do ensino médio da escola Figueiredo Correia quando mencionou "que o estudo da Biologia nos ajuda a evitar a poluição das ruas e dos rios de nosso meio ambiente". Portanto, identificamos de fato a importância de tal disciplina para realidade concreta dos alunos, pois para maioria deles a biologia esta diretamente ligada, e em intensa interconexão com seus cotidianos, o que implica um olhar crítico em relação ao mundo que vivem.

No segundo quadro identificamos nas respostas dos alunos, uma constatação bastante problemática no que se refere a realização de aulas práticas em laboratórios de Ciências, das escolas pesquisadas. Na escola Gabriel Ferreira 100\% dos alunos afirmaram que nunca tiveram aulas práticas de biologia, sendo importante ressaltar que a escola não possui laboratório, já na Escola Figueiredo Correia, apesar de possuir laboratório, 81\% dos alunos afirmaram nunca terem participado de aulas práticas no laboratório de Ciências, e $19 \%$ afirmaram que somente as vezes participam de tais atividades. Esses números nos indicam um grande problema na oferta de aulas práticas para estes alunos em ambas as escolas, o que fica evidente ainda uma predominância de um ensino essencialmente teórico.

Quadro 2 - Frequência de aulas práticas no laboratório de Ciências.

\begin{tabular}{|l|c|c|c|c|c|c|}
\hline & \multicolumn{2}{|c|}{$\begin{array}{c}\text { Figueiredo Correia } \\
\text { (Fortaleza) }\end{array}$} & \multicolumn{2}{c|}{$\begin{array}{c}\text { Gabriel Ferreira } \\
\text { (Teresina) }\end{array}$} & \multicolumn{2}{c|}{ Total } \\
\hline RESPOSTAS & Frequência & $\%$ & Frequência & $\%$ & Frequência & $\%$ \\
\hline Sempre & 0 & 0 & 0 & 0 & 0 & 0 \\
\hline Às vezes & 12 & 19 & 0 & 0 & 12 & 8 \\
\hline Nunca & 50 & 81 & 84 & 100 & 134 & 92 \\
\hline Total & 62 & 100 & 84 & 100 & 146 & 100 \\
\hline
\end{tabular}

Fonte: Realizada pelos autores.

No terceiro quadro apontamos os dados referentes a perspectiva dos alunos no que se refere a frequência do professor em relacionar a Biologia com as demais disciplinas do ensino básico das escolas. Nesse caso, $73 \%$ dos alunos da escola Figueiredo Correia responderam que os professores de Biologia não fazem essa interligação com as demais disciplinas. Na escola Gabriel Ferreira, $60 \%$ dos alunos também responderam que o professor não interage com outras disciplinas. No total das duas realidades escolares $65 \%$ dos alunos colocam como negativa a interação interdisciplinar dos professores de Biologia 
para com as outras áreas do conhecimento. Portanto, identificamos outra deficiência no que se refere a questão da interdisciplinaridade entre as áreas do conhecimento, ou seja, na visão dos alunos os professores não tem priorizado em suas atividades tal interação entre as disciplinas, fato este que dificulta o processo de ensino e aprendizagem no que tange correlacionar a Biologia com as outras áreas do saber, o que acaba por limitar o olhar do aluno, e o prejudica para uma visão mais ampla do conhecimento.

Quadro 3 - A perspectiva dos alunos no que se refere a frequência do professor em relacionar a Biologia com as demais disciplinas.

\begin{tabular}{|l|c|c|c|c|c|c|}
\hline & \multicolumn{2}{|c|}{$\begin{array}{c}\text { Figueiredo Correia } \\
\text { (Fortaleza) }\end{array}$} & \multicolumn{2}{|c|}{$\begin{array}{c}\text { Gabriel Ferreira } \\
\text { (Teresina) }\end{array}$} & \multicolumn{2}{c|}{ Total } \\
\hline RESPOSTAS & Frequência & $\%$ & Frequência & $\%$ & Frequência & $\%$ \\
\hline Sim & 17 & 27 & 34 & 40 & 51 & 35 \\
\hline Não & 45 & 73 & 50 & 60 & 95 & 65 \\
\hline Total & 62 & 100 & 84 & 100 & 146 & 100 \\
\hline
\end{tabular}

Fonte: Realizada pelos autores.

No quarto quadro foram analisados os tipos de aulas mais frequentes no semestre, onde $85 \%$ do total de alunos das escolas Figueiredo Correia e Gabriel Ferreira apontaram que a aula expositiva é o tipo mais frequente, e apenas $6 \%$ dos alunos afirmaram maior frequência em aulas do tipo prática nas escolas.

Quadro 4 - O tipo de aula mais frequente no semestre de acordo com a posição dos alunos.

\begin{tabular}{|l|c|c|c|c|c|c|}
\hline & \multicolumn{2}{|c|}{$\begin{array}{c}\text { Figueiredo Correia } \\
\text { (Fortaleza) }\end{array}$} & \multicolumn{2}{c|}{$\begin{array}{c}\text { Gabriel Ferreira } \\
\text { (Teresina) }\end{array}$} & \multicolumn{2}{c|}{ Total } \\
\hline RESPOSTAS & Frequência & $\%$ & Frequência & $\%$ & Frequência & $\%$ \\
\hline Expositiva & 56 & 85 & 75 & 87 & 131 & 85 \\
\hline Prática & 3 & 5 & 5 & 5 & 8 & 6 \\
\hline No Laboratório & 0 & 0 & 0 & 0 & 0 & 0 \\
\hline Com audiovisuais & 5 & 7 & 6 & 7 & 11 & 7 \\
\hline Outro tipo & 2 & 3 & 1 & 1 & 3 & 2 \\
\hline Total & 66 & 100 & 87 & 100 & 153 & 100 \\
\hline
\end{tabular}

Fonte: Realizada pelos autores. 
No quinto quadro foram apontadas as questões no que se refere ao professor conciliar a teoria do livro didático com aulas práticas. Assim, considerando o número total de alunos das duas escolas temos que $46 \%$ dos alunos afirmaram que o professor nunca concilia a teoria com a prática, $37 \%$ afirmaram que as vezes os professores conseguem aliar a teoria do livro com a prática, e somente $17 \%$ afirmaram que sempre os professores conseguem conciliar as duas perspectivas.

Quadro 5 - Percepção dos alunos no que se refere ao professor conciliar a teoria do livro didático com aulas práticas.

\begin{tabular}{|l|c|c|c|c|c|c|}
\hline & \multicolumn{2}{|c|}{$\begin{array}{c}\text { Figueiredo Correia } \\
\text { (Fortaleza) }\end{array}$} & \multicolumn{2}{c|}{$\begin{array}{c}\text { Gabriel Ferreira } \\
\text { (Teresina) }\end{array}$} & \multicolumn{2}{c|}{ Total } \\
\hline RESPOSTAS & Frequência & $\%$ & Frequência & $\%$ & Frequência & $\%$ \\
\hline Sempre & 10 & 14 & 16 & 19 & 26 & 17 \\
\hline Às vezes & 27 & 38 & 23 & 28 & 57 & 37 \\
\hline Nunca & 34 & 48 & 44 & 53 & 71 & 46 \\
\hline Total & 71 & 100 & 83 & 100 & 154 & 100 \\
\hline
\end{tabular}

Fonte: Realizada pelos autores.

Com a análise dos dados considerando o quarto e o quinto quadro podemos observar que a dificuldade de aliar a teoria com a prática persiste e ainda é um desafio a ser superado pelos professores de Biologia. Tanto é isso, que apenas uma pequena porcentagem, de alunos, afirmaram ser frequente a utilização de outros tipos de aulas, do que somente a tradicional aula expositiva como observamos no quarto quadro.

No sexto quadro abordou-se a questão da importância do ensino de Biologia na formação do discente enquanto cidadão, onde $93 \%$ do total de alunos em análise nas duas escolas afirmaram que o ensino de Biologia é de fundamental importância para sua formação e desenvolvimento, o que demonstra uma consciência dos alunos no reconhecimento desta área do saber para sua formação como um todo.

Quadro 6 - Opinião dos alunos no que se refere a importância da Biologia para sua formação enquanto cidadão.

\begin{tabular}{|l|c|c|c|c|c|c|}
\hline & \multicolumn{2}{|c|}{$\begin{array}{c}\text { Figueiredo Correia } \\
\text { (Fortaleza) }\end{array}$} & \multicolumn{2}{c|}{$\begin{array}{c}\text { Gabriel Ferreira } \\
\text { (Teresina) }\end{array}$} & \multicolumn{2}{c|}{ Total } \\
\hline RESPOSTAS & Frequência & $\%$ & Frequência & $\%$ & Frequência & $\%$ \\
\hline Sim & 57 & 92 & 79 & 94 & 136 & 93 \\
\hline Não & 5 & 8 & 5 & 6 & 10 & 7 \\
\hline Total & 62 & 100 & 84 & 100 & 146 & 100 \\
\hline
\end{tabular}

Fonte: Realizada pelos autores. 
Por último, o sétimo quadro em análise refere-se ao tipo de aula que os alunos acham mais interessante e que pode contribuir para o desenvolvimento de uma aprendizagem mais significativa. Nessa direção, considerando o total de alunos das duas escolas, 34\% afirmaram ser mais interessante, as aulas de laboratórios, já $26 \%$ as práticas, $22 \%$ as expositivas, $16 \%$ as com utilização de audiovisuais, e $2 \%$ de outros tipos. Isto demonstra e indica uma maior preferência por parte dos alunos a outras possibilidades de ensino, do que somente o modelo tradicional.

Quadro 7 - O tipo de aula mais interessante de acordo com a posição dos alunos.

\begin{tabular}{|l|c|c|c|c|c|c|}
\hline & $\begin{array}{c}\text { Figueiredo Correia } \\
\text { (Fortaleza) }\end{array}$ & $\begin{array}{c}\text { Gabriel Ferreira } \\
\text { (Teresina) }\end{array}$ & \multicolumn{2}{|c|}{ Total } \\
\hline RESPOSTAS & Frequência & $\%$ & Frequência & $\%$ & Frequência & $\%$ \\
\hline Expositiva & 12 & 15 & 25 & 28 & 37 & 22 \\
\hline Com audiovisuais & 16 & 20 & 12 & 13 & 28 & 16 \\
\hline Prática & 16 & 20 & 28 & 31 & 44 & 26 \\
\hline No laboratório & 33 & 43 & 22 & 24 & 55 & 34 \\
\hline Outro tipo & 2 & 2 & 2 & 4 & 4 & 2 \\
\hline Total & 79 & 100 & 89 & 100 & 168 & 100 \\
\hline
\end{tabular}

Fonte: Realizada pelos autores.

A teoria aliada a prática, em interconexão com outras possibilidades de ensino estimula nos alunos a capacidade cognitiva de perceber a importância da disciplina de biologia para sua formação enquanto cidadão crítico. Isto implica diretamente no interesse efetivo do aluno pela experiência científica e transformadora do ensino. Dessa forma, diante dos resultados dos questionários, no qual priorizamos as respostas dos alunos podemos afirmar que aliar teoria à prática é um desafio ainda a ser superado no processo de ensino e aprendizagem. É possível perceber também que o ensino de Biologia ainda é deficiente em articular a teoria com o cotidiano dos alunos, uma problemática que dificulta o processo de ensino em sua totalidade.

Além da análise dos questionários utilizamos também do processo da observação, no qual, contamos com o auxílio de um diário para melhor registro de nossas observações, e com o objetivo de detalhar os momentos vivenciados nas escolas e da realização das entrevistas, em uma perspectiva mais qualitativa. Realizamos entrevistas com os líderes de turma de cada série e com os professores da disciplina de Biologia em exercício nas escolas. 
Nossa análise qualitativa veio a confirmar os dados quantitativos colhidos nos questionários, entretanto, algumas questões merecem atenção especial. Como por exemplo, a percepção de alguns alunos no que se refere à deficiência do professor em ministrar a disciplina, além das constantes paralisações no ensino público.

Primeiro, a falta de professor qualificado! Eu acho que os professores não estão tendo a qualificação certa para estar aplicando esse tipo de matéria para gente, e a questão é que aqui, tem muita paralização e a gente acaba se prejudicando por causa disso. O ensino de biologia não esta mais essa coisa toda! Tem coisas, que aluno em colégio particular está vendo, [...] e que a gente já devia ter visto. Então é uma coisa que não esta sendo aplicada, em minha opinião, eu não estou achando que aqui está sendo aplicado direito. (M.C.M, Aluna do $2^{\circ}$ ano do Ensino Médio da Unidade Escolar Gabriel Ferreira).

Eu acho que, tipo, a professora explica muito bem! Mas só que ás vezes, ela comete alguns erros, [...] algumas coisas ela não sabe explicar bem, e acho que deveria ter mais aulas práticas, e não ficar só na teoria. (V. M., Aluno do $1^{\circ}$ ano do Ensino Médio da EEFM Figueiredo Correia).

Podemos perceber pela fala dos alunos que existe um desafio a ser enfrentado pelos professores de biologia no que se refere ao ensino propriamente dito da disciplina tanto no plano teórico como no prático, a partir dessas observações é importante destacar que os alunos estão em intensa avaliação em sala de aula.

Outra questão importante evidenciada neste trabalho se refere a ausência de políticas públicas mais efetivas no tocante a capacitação e aperfeiçoamento dos professores da rede estadual de ensino, pois quando estas acontecem, se dão de maneira dispersa e descontínua. Recentemente, "de uns três anos para cá [...] ele [Estado do Piauí] tem oferecido cursos à distância”, afirma o professor de Biologia, M. A, da Escola Gabriel Ferreira.

A professora de Biologia, R. G, da EEFM Figueiredo Correia também faz essa crítica:

Ele [Estado] deu uma parada na formação continuada. Quando eu ingressei no Estado, eles ofereceram especialização, agora, em nível de Estado, nós estamos sem suporte de treinamento. De, como é que eu posso dizer? De reciclagem dos professores. O que a gente tem, é em termos federais, que eles estão estadualizando. [...] é o pacto nacional do ensino médio, que eu acho que é uma das maiores conquistas dos professores em termos, [...] de tentar a interdisciplinaridade, e tentar um currículo mais enxuto e menos extenso. (R. G, professora de Biologia do Ensino médio da Escola EEFM Figueiredo Correia).

A partir desse contexto evidenciamos algumas deficiências em relação a gestão pública, no que se refere à educação estadual e ao suporte que a escola e os professores necessitam para trabalhar e possibilitar o desenvolvimento de competências e habilidades dos alunos. Além da capacitação profissional e qualificação para os professores, as escolas precisam de recursos que estejam ao alcance do professor, para oferecer um ensino de 
qualidade. No ensino de biologia, além de outros equipamentos e recursos, o laboratório constitui uma ferramenta essencial que deve vir acompanhado de professores qualificados para a realização das atividades (PAGLIARINE, et al, 2013).

Portanto, podemos destacar a importância da atualização dos professores de biologia para uma formação continuada, principalmente, no que se refere às novas tecnologias advindas de um intenso processo de informatização buscando novas técnicas e métodos do que, e como ensinar de acordo com sua realidade especifica, levando ao aluno um ensino de qualidade que contemple a relação entre a teoria e a prática, e que instigue o professor a estar sempre buscando uma renovação e reavaliação de suas atividades.

Através das observações e constatações alcançadas pela pesquisa em questão, é importante destacar ainda que é necessária a ampliação das políticas públicas educacionais nos estados do Piauí e Ceará e medidas mais eficazes que garantam aos gestores e alunos da rede pública Estadual de ensino condições para uma educação de qualidade.

\section{Considerações finais}

No decorrer da pesquisa foi possível observar o contexto escolar dos alunos e das escolas trabalhadas, fato este, que teve significativa importância, para a construção do presente trabalho científico. Pôde-se observar que o ensino de Biologia na rede pública estadual de ensino ainda perpassa intensa deficiência no que diz respeito a conciliar teoria e prática nas aulas de Biologia. A falta de recursos didáticos torna o desafio ainda mais difícil, a falta de formação continuada para os docentes também é um ponto que deixa a desejar em ambos os estados na realidade das escolas pesquisadas.

Percebemos durante as entrevistas a insatisfação dos alunos no tocante as aulas de Biologia, em muitas ocasiões, causada até mesmo pela falta de capacitação do professor, expressada nas entrevistas com os alunos, e pela falta de recursos do ensino público estadual. A capacitação dentro da formação continuada precisa e tem a finalidade de transformar o professor em um profissional prático-reflexivo preparado para enfrentar situações diversas dentro da sala de aula e fora dela, daí a importância dessa formação para professores no exercício da educação (IMBERNÓN, 2010).

Nessa direção, contextualização e interdisciplinaridade atuam de maneira conjunta no exercício da educação e contribui para a formação do aluno frente aos desafios da vida em sociedade (FORTES, 2009). Dentro dessa perspectiva, o uso de novas metodologias mostra-se como um caminho possível, entretanto, observou-se que a maioria dos professores de biologia, ainda se utiliza de uma metodologia mais tradicional, e com poucas aulas em laboratório. Não só por opção metodológica, mas também por falta de recursos didáticos e incentivos efetivos quanto à formação continuada.

A formação do discente no processo de ensino-aprendizagem é um fato que requer atenção maior. Contudo, diante da coleta de dados e da construção da pesquisa observouse que os professores não contemplam a interdisciplinaridade de forma efetiva e segundo 
os alunos os professores não estabelecem esta interconexão com as demais áreas do ensino.

Enfim, a participação dos alunos foi bastante satisfatória, e o diálogo com os professores deu ênfase a qualidade das informações. Para grande parte dos alunos o ensino de Biologia poderia ter mais êxito se os professores aliassem à teoria com a prática, no sentido de realizarem aulas mais dinâmicas para uma aprendizagem significativa. Portanto, teoria aliada a prática, além do uso de novas metodologias constituem ferramentas essenciais para construção de um saber sólido e contextualizado no âmbito do Ensino de biologia para o Ensino Médio.

\section{Referências}

APPOLINÁRIO, F. Introdução à Análise Qualitativa de Dados. In: Metodologia Científica. Filosofia e Prática da Pesquisa. São Paulo: Thomson Learning, 2006, pp, 136 - 184.

BRASIL, Secretária de Educação média e Tecnológica. Parâmetros Curriculares Nacionais: Ensino Médio. Brasília: Ministério da Educação, 2000.

BRASIL. Conselho Nacional de Educação (CNE). Resolução n. 2, de 30 de janeiro de 2012. Diretrizes Curriculares Nacionais para o Ensino Médio. Brasília, DF, 2012.

BRASIL. Ministério da Educação (MEC), Secretária de Educação Básica (SEB), Departamento de Políticas do Ensino Médio (DPEM). Orientações Curriculares Para o Ensino Médio: MEC/ SEB, 2006.

BUENO, R. S. M; KOVALICZN, R. A. O Ensino de Ciências e as Dificuldades das Atividades Experimentais. Artigos relacionados. Secretaria da Educação. Paraná - 2008. Disponível em: http://www.diaadiaeducacao.pr.gov.br/portals/pde/arquivos/23-4.pdf. Acesso em: 11 fev. 2015.

CARLOS, J. G. Interdisciplinaridade no Ensino Médio: Desafios e Potencialidades. Dissertação (Mestrado Profissionalizante em Ensino de Ciências). Universidade de Brasília, 2006.

CHAGAS, A. T. R. O Questionário na Pesquisa Científica. USP, 2000. Disponível em: http://www.fecap.br/adm online/art11/anival.htm. Acesso em: 15 fev. 2015.

FORTES, C. C. Interdisciplinaridade: Origem, Conceito e Valor. Artigos relacionados. Revista acadêmica SENAC on-line. UFSM, 2009.

GOlDENBERG, M. A Arte de Pesquisar. Rio de Janeiro: Record, 2001.

GONZAGA, P. C. et al. A Prática de Ensino de Biologia em Escolas Públicas: Perspectivas na Visão de Alunos e Professores. XVI ENDIPE - Encontro Nacional de Didática e Práticas de Ensino - UNICAMPI - Campinas - 2012, 10 p. Disponível em: http://www.infoteca.inf.br/endipe/smarty/templates/arquivos template/upload arquivos/ace rvo/docs/2600p.pdf. Acesso em: 11 fev. 2015.

IMBERNÓN, F. A Profissão docente Diante dos Desafios da Chamada Sociedade Globalizada, do Conhecimento ou da Informatização. In: Formação Docente e 
Profissional: Formar-se para a mudança e a incerteza/ Francisco Imbernón; [tradução Silvana Cobucci Leite]. - 8. ed. - São Paulo: Cortez, 2010, pp, 38 - 44, (Coleção questões da nossa época; v. 14).

KOVALICZN, R. A. O Professor de Ciências e Biologia Frente as Parasitoses Comuns e Escolares. Dissertação (Mestrado em Educação). UEPG, 1999.

MARTINS JUNIOR, J. Instrumentos de coleta de Dados. In: Como Escrever Trabalhos de Conclusão de Curso: Instruções para planejar e montar, desenvolver, concluir, redigir e apresentar trabalhos monográficos e artigos/ Joaquim Martins Junior. 4. ed. - Petrópolis, RJ: Vozes, 2010, pp, $195-220$.

OLIVEIRA, V. H. M; DANTAS, L. P. A. Biologia em Verso e Prosa: Ensinando através de Cordéis. Artigo (Trabalho de Conclusão de Curso). IFPI, 2014.

PAGLIARINE, D. S. et al. Revitalização do Laboratório de Biologia da Escola Estadual de Ensino Médio Cilon Rosa. VI Encontro Regional Sul de Ensino de Biologia, XVI Semana Acadêmica de Ciências Biológicas, URI - Santo Ângelo, Rio Grande do Sul, 22 a 24 de maio de 2013.

REZENDE, R. C. S; SILVA, M. A. D. Diagnóstico do ensino de biologia em escolas públicas de llhéus e Itabuna (BA). In. XIII Seminário de Iniciação Científica e 9a Semana de pesquisa e Pós-Graduação da UESC Ciências Humanas, 2007. Disponível em: http://www.uesc.br/seminarioic/sistema/resumos/2007262.pdf. Acesso em: 16 fev. 2015

SILVA, F. S. S. et al. Dificuldades dos Professores de Biologia em Ministrar Aulas Práticas em Escolas Públicas e Privadas do Município de Imperatriz (MA). Artigos relacionados (Educação, Políticas Públicas e Sociedade). UNI, 2013. Disponível em: https://scholar.google.com.br/scholar. Acesso em: 12 fev. 2015.

TEIXEIRA, L. C. R. S; OLIVEIRA, A. M. A Relação Teoria-Prática na Formação do Educador e Seu Significado para a Prática Pedagógica do Professor de Biologia. UFMG, 2008.

ZAMUNARO, A. N. B. R. A Prática de Ensino de Ciências e Biologia e Seu Papel na Formação de Professores. Bauru: Universidade Estadual Paulista, 2006. Dissertação (Tese de Doutorado em Educação Para a Ciência). Disponível em: http://www.educadores.diaadia.pr.gov.br/arquivos/File/2010/artigos teses/Ciencias/Teses/ tesezamunaro.pdf. Acesso em: 13 fev. 2015.

Submissão: $12 / 11 / 2016$

Aceite: $21 / 06 / 2017$ 